\title{
Multimodal preoperative evaluation system in surgical decision making for rectal cancer: a randomized controlled trial
}

\author{
Xiaodong Wang • Donghao Lv • Huan Song • Lei Deng • \\ Qiang Gao $\cdot$ Junhua Wu $\cdot$ Yingyu Shi $\cdot$ Li Li
}

Accepted: 27 October 2009/Published online: 18 November 2009

(C) The Author(s) 2009. This article is published with open access at Springerlink.com

\begin{abstract}
Purpose Multimodal preoperative evaluation (MPE) is a novel strategy for surgical decision making, incorporating the transrectal ultrasound (TRUS), 64 multi-slice spiral computer tomography (MSCT), and serum amyloid A protein (SAA) for rectal cancer. This trial aims to determine the accuracy of MPE in preoperative staging and its role in surgical decision making for rectal cancer.

Methods Two hundred twenty-five participants with histologically proven rectal cancer with tumor height less than $10 \mathrm{~cm}$ were randomly assigned into three arms

Source of support Funded by Sichuan Provincial Health Department Research Project (N0. 080278)

Contribution of authors Donghao Lv, Xiaodong Wang, and Li Li designed this trial and prepared the protocol. Xiaodong Wang, Junhua $\mathrm{Wu}$, Yingyu Shi, and Donghao Lv made the preoperative staging for enrolled participants. Huan Song and Qiang Gao collected the data. Donghao Lv and Lei Deng pooled the data into analysis and gave the interpretation of results. Donghao Lv, Xiaodong Wang, and $\mathrm{Li} \mathrm{Li}$ prepared this manuscript.
\end{abstract}

\section{Wang $\cdot$ L. Li $(\triangle)$}

Anal-Colorectal Surgery, West China Hospital,

Sichuan University,

37, Guo Xue Xiang,

Chengdu, China 610041

e-mail: drlili116@126.com

D. Lv $\cdot$ H. Song $\cdot$ L. Deng $\cdot$ Q. Gao

West China School of Medicine, Sichuan University,

Chengdu, China

\section{J. Wu}

Radiology, West China Hospital,

Chengdu, China

Y. Shi

Sonography, West China Hospital,

Chengdu, China in the ratio 1:1:1. Arm A (MPE) was multimodal staged by the combination of MSCT, TRUS, and SAA. Arm B (MSCT+SAA) was staged by MSCT and SAA. Arm C (MSCT) was staged only by MSCT. The primary endpoints were the accuracy of preoperative staging and expected surgical procedures. This study is registered as an International Standard Randomised Controlled Trial, number ChiCTR-DT-00000409.

Results The analysis showed statistical difference in the accuracy of $\mathrm{T}$ staging between arm $\mathrm{A}$ and $\mathrm{B}(94.6 \%$ vs. $77.8 \%, P=0.003)$ and arm A and C (94.6\% vs. $80.6 \%, P=$ 0.010 ). Statistical difference was also observed between the accuracies of preoperative $\mathrm{N}$ staging between arm $\mathrm{A}$ and $\mathrm{C}$ (85.1\% vs. $69.4 \%, P=0.023)$ and arm A and $\mathrm{B}(85.1 \%$ vs. $84.7 \%, P=0.029)$. Surgical decision making in arm A was more accurate than that in arm $\mathrm{C}(95.9 \%$ vs. $80.6 \%, P=$ $0.001)$. Pathological T stage $(P<0.001)$, N stage $(P<0.001)$, tumor node metastasis stage $(P<0.001)$, serum level of SAA $(P=0.002)$, and tumor height $(P=0.030)$ were significantly associated with final surgical procedures.

Conclusion MPE is an effective strategy in preoperative staging and more accurate than other available strategies in surgical decision making for rectal cancer.

Keywords Rectal cancer - Surgical procedures · Multi-slice spiral computer tomography · Transrectal ultrasound · Serum amyloid A protein $\cdot$ Multimodal preoperative evaluation

\section{Introduction}

Preoperative evaluation of rectal carcinoma is crucial in the decision making of preoperative treatment and surgical procedures. All the choices of surgical procedures, e.g., extended surgery or local excision for rectal cancer, should 
be tailored on the basis of accurate preoperative staging [1-4]. Recently, the evidence-based move to selective preoperative chemoradiotherapy for selected patients has intensified the need to develop accurate image-based staging systems [5]. Additionally, the use of preoperative therapies may have dramatic effects on the consequential pathological findings. Therefore, accurate details prior to treatment are essential [6].

Various staging modalities for rectal cancer include transrectal ultrasound (TRUS), computed tomography (CT), and MR imaging (MRI) with or without endorectal coil. Current evidence shows that TRUS is the most established and preferred modality for $\mathrm{T}$ staging of rectal cancer [7]; however, no ideal imaging technique is available for evaluation of metastatic lymph nodes [8]. The multidetector CT is still the first option for distant metastatic diseases [9].

Serum amyloid A protein (SAA), also termed as acute phase protein, is a major factor in altering high-density lipoproteins metabolism during inflammation [10]. Glojnaric et al. [11] reported a significant increase of SAA level in patients with colorectal cancer. More recent study showed that an increased SAA level was associated with metastatic lymph nodes in rectal cancer, which indicated the potential value for preoperatively noninvasive identification of lymph nodes [12]. Our previous study confirmed that the preoperative evaluation strategy combining 64 multi-slice spiral computer tomography (MSCT) with SAA improved the accuracy of preoperative staging, particularly in $\mathrm{N}$ staging. This strategy was more useful in planning the surgical resection than MSCT alone as well [13].

In this prospective, randomized, and controlled study, the multimodal preoperative evaluation (MPE) system was set for surgical decision making in rectal cancer, incorporating TRUS, MSCT, and SAA. The MPE system uses TRUS for T staging, MSCT for M staging, and assesses N stage based on MSCT with SAA for identification. This trial aims to determine the accuracy of MPE in preoperative staging and its role in surgical decision making for rectal cancer. In order to clarify the role of MPE in surgical decision making, this trial is designed as a randomized controlled study.

\section{Materials and methods}

All the study subjects were proven to be histologically confirmed colorectal cancer patients. Eligibility criteria included tumor height (proximal from dentate line) less than $10 \mathrm{~cm}$ assessed by colonoscopy, tumor which can be passed completely during colonoscopy, and operable diseases. Exclusion criteria included patients with a history of infection within the previous 1 month; immune system disease history; and inflammatory bowel disease, bowel obstruction, or a history of chronic diarrhea; and a neoadjuvant treatment history.

This was a prospective, single-center, randomized trial conducted between July 2008 and March 2009. Patients were randomly assigned into three arms in the ratio $1: 1: 1$ done by a computer-generated randomization list. Concealment of treatment allocation was achieved with the use of sealed opaque envelops each containing a unique study number and prepared independently by a secretary.

Three arms were compared, each with a different workup of technique for preoperative staging. Arm A $(n=75)$ was multimodal staged by the combination of MSCT, TRUS, and SAA. Arm B $(n=75)$ was staged by MSCT and SAA. Arm C $(n=75)$ was the control group, staged only by MSCT.

MSCT examinations were performed for all patients in three arms by using a Philips Brilliance 64-slice CT scanner (Philips Medical Systems, Best, The Netherlands). Before MSCT examination, all patients were prepared with laxative and enema. Sufflation of approximately $100 \mathrm{ml}$ of air into the rectum was performed, and sequences were obtained with one breath-hold from the level of the diaphragm to the anus in approximately $10 \mathrm{~s}$. The slice interval was adjusted to $5 \mathrm{~mm}$. Imaging of MDCT was obtained using multiplanar reformation technique. Enhancement medium (Omnipaque: GE Healthcare, Buckinghamshire, United Kingdom) was administered intravenously for all patients. Computed tomography was prospectively evaluated prior to surgery by one radiologist (Junhua $\mathrm{Wu}$ ). The reader was blinded to any patient information. The CT scans were assessed for the depth of tumor invasion and the presence of regional lymph node metastases. CT-tumor node metastasis (TNM) stage was performed according to the Thoeni's classification (Table 1) [14]. Metastatic lymph nodes were considered to be present if their diameter exceeded $8 \mathrm{~mm}$.

TRUS was performed for arm A by using a Philips HDI 5000 ultrasound scanner (Philips Medical Systems, Bothell, WA, USA). The rectal probe measures $16 \mathrm{~cm}$ in length with a head diameter of $21 \mathrm{~mm}$. During the examination, the frequency can be switched from $7.5 \mathrm{MHz}$ to $5 \mathrm{MHz}$ with a maximum tissue penetration of approximately $7 \mathrm{~cm}$ for the latter. The beams can be emitted in line with or transverse to the longitudinal axis of the rectum. TRUS was prospectively evaluated prior to surgery by one ultrasonologist (Yingyu Shi) who have more than 5-year experience on TRUS. The reader was blinded to any patient information. The TRUS scans were assessed for the depth of tumor invasion following Hildenbrandt's principles (Table 1) [15].

Venous blood specimens in arm A and B were taken on the third day before surgery and sent to Clinical Immunology Laboratory for test. SAA concentration was measured by immunofixed time nephelometry (Dade Behring Diagnostics). The serum SAA level was measured according to the manufacturer's instructions. In the meantime, venous blood 
Table 1 The preoperative staging standards of three arms

\begin{tabular}{|c|c|c|c|}
\hline $\begin{array}{l}\text { Preoperative } \\
\text { TNM stage }\end{array}$ & Arm A (MPE) & Arm B (MSCT and SAA) & Arm C (MSCT) \\
\hline \multicolumn{4}{|l|}{ T stage } \\
\hline $\mathrm{T} 1$ & $\begin{array}{l}\text { Submucosa was irregularly thinned by a } \\
\text { hypoechoic tumor mass showed by TRUS }\end{array}$ & $\begin{array}{l}\text { Intraluminal polypoid mass without thickening } \\
\text { of the bowel wall showed by MSCT }\end{array}$ & $\begin{array}{l}\text { Intraluminal polypoid mass } \\
\text { without thickening of the bowel } \\
\text { wall showed by MSCT }\end{array}$ \\
\hline $\mathrm{T} 2$ & $\begin{array}{l}\text { Complete disruption of submucosa, often } \\
\text { with thickening of the muscularis propria } \\
\text { showed by TRUS }\end{array}$ & & \\
\hline $\mathrm{T} 3$ & $\begin{array}{l}\text { The border between the muscularis propria and } \\
\text { serosa or perirectal fat was irregular or } \\
\text { serrated showed by TRUS }\end{array}$ & $\begin{array}{l}\text { Thickening of the bowel wall }(>0.5 \mathrm{~cm}) \\
\text { without invasion of surrounding tissue } \\
\text { showed by MSCT }\end{array}$ & $\begin{array}{l}\text { Thickening of the bowel wall } \\
(>0.5 \mathrm{~cm}) \text { without invasion of } \\
\text { surrounding tissue showed by } \\
\text { MSCT }\end{array}$ \\
\hline $\mathrm{T} 4$ & $\begin{array}{l}\text { Extension to the adjacent structures or organs } \\
\text { showed by TRUS }\end{array}$ & $\begin{array}{l}\text { Invasion of surrounding tissue walls showed } \\
\text { by MSCT }\end{array}$ & $\begin{array}{l}\text { Invasion of surrounding tissue } \\
\text { walls showed by MSCT }\end{array}$ \\
\hline \multicolumn{4}{|l|}{$\mathrm{N}$ stage } \\
\hline No & $\begin{array}{l}\text { No visible lymph node, or a lymph node } \\
\text { (diameter }<8 \mathrm{~mm} \text { ) showed by MSCT with } \\
\text { SAA level }<3.30 \mathrm{mg} / \mathrm{L}\end{array}$ & $\begin{array}{l}\text { No visible lymph node, or a lymph node } \\
\text { (diameter }<8 \mathrm{~mm} \text { ) showed by MSCT with } \\
\text { SAA level }<3.30 \mathrm{mg} / \mathrm{L}\end{array}$ & $\begin{array}{l}\text { No visible lymph node, or a } \\
\text { lymph node (diameter }<8 \mathrm{~mm} \text { ) } \\
\text { showed by MSCT }\end{array}$ \\
\hline N1 & $\begin{array}{l}\text { 1. A lymph node (diameter }<8 \mathrm{~mm} \text { ) showed } \\
\text { by MSCT but SAA level } \geq 3.30 \mathrm{mg} / \mathrm{L} ; 2 \text {. } \\
\text { serum SAA level } \geq 8.90 \mathrm{mg} / \mathrm{L} \text {; and } 3 \text {. a } \\
\text { lymph node (diameter } \geq 8 \mathrm{~mm} \text { ) was } \\
\text { measured by MSCT }\end{array}$ & $\begin{array}{l}\text { 1. A lymph node (diameter }<8 \mathrm{~mm} \text { ) showed } \\
\text { by MSCT but SAA level } \geq 3.30 \mathrm{mg} / \mathrm{L} ; 2 \text {. } \\
\text { serum SAA level } \geq 8.90 \mathrm{mg} / \mathrm{L} \text {; and } 3 \text {. a } \\
\text { lymph node (diameter } \geq 8 \mathrm{~mm} \text { ) was } \\
\text { measured by MSCT }\end{array}$ & $\begin{array}{l}\text { A lymph node (diameter } \\
\geq 8 \mathrm{~mm} \text { ) was measured by } \\
\text { MSCT }\end{array}$ \\
\hline \multicolumn{4}{|c|}{ 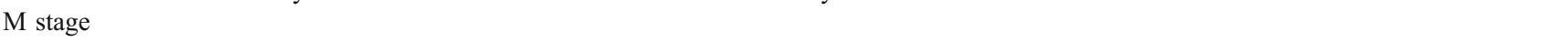 } \\
\hline M0 & No distant metastases were found by MSCT & No distant metastases were found by MSCT & $\begin{array}{l}\text { No distant metastases were found } \\
\text { by MSCT }\end{array}$ \\
\hline M1 & Distant metastases were found by MSCT & Distant metastases were found by MSCT & $\begin{array}{l}\text { Distant metastases were found by } \\
\text { MSCT }\end{array}$ \\
\hline
\end{tabular}

samples were also submitted to Clinical Blood Laboratory for a blood routine test in order to exclude inflammatory cases.

Surgeons collected the information of preoperative evaluation and performed the preoperative staging according to Table 1 [13]. Two senior surgeons developed expected surgical procedures according to preoperative evaluation together and performed the final operative procedures. Surgical procedures were classified as sphincter-preserving radical excision, non-sphincter-preserving radical excision, and palliative colostomy. In nearly all the cases, surgery was performed within a week. Resected specimens were examined by pathologists without knowing the preoperative findings. The pathological findings were assessed according to TNM classification of colorectal cancer, 6th edition, by American Joint Committee on Cancer [16].

The primary endpoints were the accuracy of preoperative staging and concordance rate of expected surgical procedures. The secondary endpoint was association between final surgical procedures and clinicopathological factors. The clinicopathological factors included tumor height, general category, texture of tumor, histology, differentiation, $\mathrm{pT}$ stage, $\mathrm{pN}$ stage, $\mathrm{pM}$ stage, pTNM stage, and preoperative serum levels of SAA.
Statistical analysis was performed by using the SPSS ${ }^{\circledR}$ version 17.0 (SPSS, Chicago, IL, USA). Continuous variables and percentages were compared between groups by using the Mann-Whitney test or chi-square test, respectively. Additionally, the Spearman test for univariate analysis was performed. $P=0.05$ (two-sided) was considered as the limit of significance.

This study is registered as an International Standard Randomised Controlled Trial, number ChiCTR-DT-00000409.

\section{Results}

From July 2008 to March 2009, 225 patients were randomized. Seven patients were excluded after randomization because of neoadjuvant chemotherapy $(n=5)$ and hospital infections before surgery $(n=2)$. The baseline characteristics relating to the remaining 218 patients (71 in Arm A, 72 in Arm B, and 72 in Arm C) are shown in Table 2. The three arms were generally well-matched in all terms. Figure 1 shows the trial profile.

Tables 3, 4, and 5 present the agreement of preoperative staging and pathological staging in three arms. Regarding 
Table 2 Baseline characteristics of three arms

\footnotetext{
${ }^{\text {a }}$ Data are medians with ranges in parentheses or numbers with percentages in parentheses.
}

\begin{tabular}{lcccc}
\hline Baseline characteristics & Arm A & Arm B & Arm C & $P$ value \\
\hline$n$ & 74 & 72 & 72 & \\
Male & $51(68.9)$ & $47(65.3)$ & $40(55.6)$ & 0.230 \\
Female & $23(31.1)$ & $25(34.7)$ & $32(44.4)$ & \\
Age (years) & $59(30-80)$ & $60.5(22-81)$ & $60(28-80)$ & 0.543 \\
Tumor height (cm) & $5(1-9)$ & $7(1-10)$ & $6(1-11)$ & 0.070 \\
Pathological TNM stage & & & & \\
I & $11(14.9)$ & $8(11.1)$ & $21(29.2)$ & 0.118 \\
II & $20(27.0)$ & $22(30.6)$ & $14(19.4)$ & \\
III & $34(45.9)$ & $36(50.0)$ & $31(43.1)$ & \\
IV & $9(12.2)$ & $6(8.3)$ & $6(8.3)$ & \\
\hline
\end{tabular}

depth of tumor invasion (Table 3 ), the overall accuracy was $94.6 \%(70 / 74)$ in $\operatorname{arm} \mathrm{A}, 77.8 \%(56 / 72)$ in arm B, and $80.6 \%(58 / 72)$ in arm C. The analysis showed that MPE had a significantly higher accuracy of $\mathrm{T}$ staging than other preoperative evaluation strategies in arm B $(P=0.003)$ and $\mathrm{C}(P=0.010)$. With regard to lymph nodes metastasis (Table 4), the accuracy, sensitivity, and specificity were $85.1 \%(63 / 74), 90.2 \%(37 / 41)$, and $78.8 \%(26 / 33)$ in arm A, 84.7\% (61/72), 85.7\% (36/42), and 83.3\% (25/30) in arm B, and 69.4\% (50/72), 54.3\% (19/35), and 83.8\% (31/ $37)$ in arm $C$, respectively. The analysis indicated that the accuracy of preoperative $\mathrm{N}$ staging was significantly different between arm $\mathrm{A}$ and $\mathrm{C}(P=0.023)$ and arm $\mathrm{A}$ and $\mathrm{B}(P=0.029)$. Moreover, the incorporation of SAA into MSCT led to significantly higher sensitivity (arm A vs. C, $P<0.001$; arm B vs. C, $P=0.002$ ), while lower specificity led to slight sensitivity (arm A vs. C, $P=0.592$; arm B vs. $\mathrm{C}, P=0.961)$. All those patients with distant metastasis were diagnosed correctly, and the accuracy of preoperative $\mathrm{M}$ staging was $100 \%$ in three arms (Table 4). As for overall preoperative TNM staging (Table 5), the accuracy of arm A was $82.4 \%(61 / 74)$, and this did not differ significantly from the figures obtained from arm B and $C(81.9 \%$ and $70.8 \%$, respectively, $P>0.05$ ).
Table 6 presents the agreement of expected surgical procedures preoperatively and final surgical procedures postoperatively in three arms. The concordance rate with final surgical procedures was $95.9 \%(71 / 74)$ in arm A, $88.9 \%(64 / 72)$ in arm B, and 80.6\% (58/72) in arm C. The analysis showed that MPE was significantly superior to preoperative MSCT evaluation strategy in prediction of surgical procedures $(P=0.001)$. No statistical difference was observed in the prediction of surgical procedures between $\operatorname{arm} \mathrm{A}$ and $\mathrm{B}$ or arm $\mathrm{B}$ and $\mathrm{C}$.

Table 7 presents that pathological T stage $(P<0.001), \mathrm{N}$ stage $(P<0.001)$, TNM stage $(P<0.001)$, serum level of SAA $(P=0.002)$, and tumor height $(P=0.030)$ were significantly associated with final surgical procedures. However, all the correlation coefficient was small. No significant association was found between final surgical procedure and general category, texture of tumor, histology, differentiation, or pM stage $(P>0.05)$.

\section{Discussion}

The results of this trial demonstrate that MPE is an effective strategy in preoperative staging and is more accurate than

Fig. 1 Trial profile

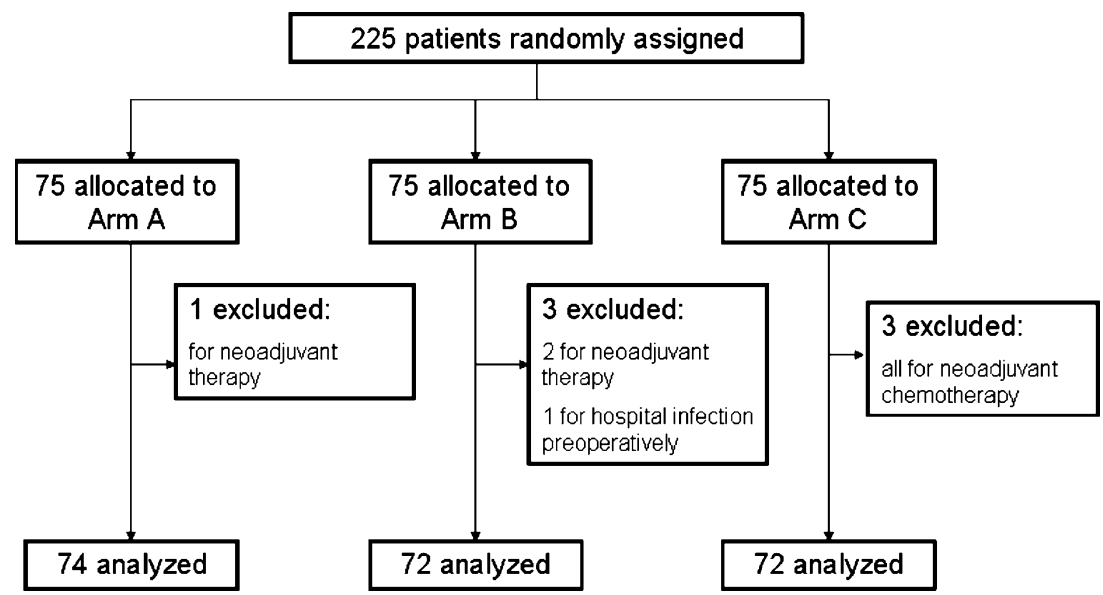


Table 3 Preoperative vs. pathological $\mathrm{T}$ staging in three arms

\begin{tabular}{|c|c|c|c|c|c|c|c|c|c|c|}
\hline \multirow[b]{2}{*}{ T stage } & \multicolumn{4}{|l|}{ Arm A } & \multicolumn{3}{|l|}{ Arm B } & \multicolumn{3}{|l|}{ Arm C } \\
\hline & preT1 & preT2 & preT3 & preT4 & preT1-2 & preT3 & preT4 & preT1-2 & preT3 & preT4 \\
\hline pT1 & 4 & 0 & 0 & 0 & 1 & 0 & 0 & 4 & 2 & 0 \\
\hline pT2 & 0 & 8 & 1 & 0 & 5 & 2 & 0 & 13 & 3 & 0 \\
\hline pT3 & 0 & 1 & 9 & 1 & 1 & 7 & 3 & 0 & 5 & 0 \\
\hline pT4 & 0 & 0 & 1 & 49 & 0 & 10 & 43 & 0 & 9 & 36 \\
\hline$n$ & 4 & 9 & 11 & 50 & 7 & 19 & 46 & 17 & 19 & 36 \\
\hline
\end{tabular}

other available strategies in surgical decision making for rectal cancer. TRUS was successfully used to assess local infiltration in MPE system and led to a significantly higher concordance rate of $94.6 \%$ than MSCT. The strategy combining MSCT with SAA to identify metastatic lymph nodes in MPE system led to higher accuracy of $85.1 \%$. Although MPE system is reported to have a non-significant increase of overall TNM staging with an accuracy of $82.4 \%$, this multimodal strategy provides the most accurate preoperative staging and effectively guides surgical decision making. However, we should draw this conclusion with a caution, due to the use of MSCT, not MRI, in this study. Many Chinese patients cannot afford the expensive cost of MRI examination, although increasing evidence show MRI is more superior on local invasion [17-19]. Thus, in this study, we use MSCT instead. The result shows MPE system based on MSCT is effective and affordable to patients in developing countries. The role of MRI in MPE system should be warranted in the future.

Our preoperative $\mathrm{T}$ staging finding supports the reported studies of TRUS superior to MSCT in local infiltration. TRUS is the most established and preferred modality for T-staging of rectal cancer with an accuracy of $64-96 \%$ [20, 21]. In comparison, even when optimized with rectal contrast, glucagon, and prone thin-slice imaging, CT is still limited for local staging because of its inherent low soft tissue contrast. This does not allow for accurate approximation of

Table 4 Preoperative vs. pathological N and M staging in three arms

\begin{tabular}{|c|c|c|c|c|c|c|}
\hline \multirow[b]{2}{*}{$\mathrm{N}$ stage } & \multicolumn{2}{|l|}{ Arm A } & \multicolumn{2}{|l|}{ Arm B } & \multicolumn{2}{|l|}{ Arm C } \\
\hline & preNo & preN1 & preN0 & preN1 & preN0 & preN1 \\
\hline pNo & 26 & 7 & 25 & 5 & 31 & 6 \\
\hline $\mathrm{pN} 1-2$ & 4 & 37 & 6 & 36 & 16 & 19 \\
\hline$n$ & 30 & 44 & 31 & 41 & 47 & 25 \\
\hline M stage & preM0 & preM1 & preM0 & preM1 & preM0 & preM1 \\
\hline pM0 & 65 & 0 & 66 & 0 & 66 & 0 \\
\hline pM1 & 0 & 9 & 0 & 6 & 0 & 6 \\
\hline$n$ & 65 & 9 & 66 & 6 & 66 & 6 \\
\hline
\end{tabular}

$\mathrm{T}$ stage unless there is gross invasion of adjacent organs [22]. Although no widely accepted protocol has been reached on the role of diagnostic imaging in the preoperative $\mathrm{T}$ staging of rectal cancer, an increasing volume of controlled studies [23-26] and two meta-analysis [7, 8] appear that TRUS provides a more accurate information for local invasion. That is the reason why TRUS is adopted for local staging in the MPE system. However, there is still some space for T staging improvements by 3-D TRUS or biopsy, after TRUS [23, 27].

The novel strategy which combined MSCT with SAA serves as a potential approach to improve the assessment of metastatic lymph nodes. Evaluation of lymph node involvement is a difficult task for radiologists. A node measuring more than $8 \mathrm{~mm}$ in the short axis is probably malignant [28]. However, enlarged nodes may be benign and reactive, whereas small nodes may be infiltrated. For rectal cancer, in particular, over half of the metastatic nodes are less than $5 \mathrm{~mm}$, which makes sense in the difficulty to evaluate lymph node involvement [29, 30]. There is a wide variation in accuracy for metastatic nodal detection with TRUS (62-87\%), CT (22-73\%), and MRI (39-75\%) [9]. Thus, current imaging techniques are comparably low in accuracy for lymph nodes staging. The main limitations are the use of size criteria, overstaging in inflammatory enlargement, and understaging in nodes beyond the range of image. Recently at the authors' institution, a novel strategy combining MSCT (or TRUS) with SAA was documented to identify inflammatory enlargement from lymph node involvement or detect the "invisible" metastatic lymph nodes by imaging since the preoperative levels of inflammatory cytokines were considered to associate with metastatic lymph nodes $[12,13,31]$. These previous studies demonstrated that the combination of MSCT with SAA or TRUS with SAA can improve the accuracy of $\mathrm{N}$ staging from $62.9-86.5 \%$ or $57.7-77.8 \%$, respectively. Similar result was observed in colonic cancer [32]. For the reason that SAA, incorporated into MSCT staging, makes more small metastatic lymph nodes diagnosed correctly, which means MSCT plus SAA leads to higher sensitivity with acceptably decreased specificity. In this study, MSCT combined with $\mathrm{SAA}$ is demonstrated to be effective in $\mathrm{N}$ staging 
Table 5 Preoperative vs. pathological TNM classification in three arms

\begin{tabular}{|c|c|c|c|c|c|c|c|c|c|c|c|c|}
\hline \multirow[b]{2}{*}{ TNM stage } & \multicolumn{4}{|c|}{ Arm A } & \multicolumn{4}{|c|}{ Arm B } & \multicolumn{4}{|c|}{ Arm C } \\
\hline & preI & preII & preIII & preIV & preI & preII & preIII & preIV & preI & preII & preIII & preIV \\
\hline $\mathrm{pI}$ & 8 & 1 & 2 & 0 & 4 & 1 & 3 & 0 & 17 & 1 & 3 & 0 \\
\hline pII & 1 & 14 & 5 & 0 & 1 & 19 & 2 & 0 & 0 & 11 & 3 & 0 \\
\hline pIII & 1 & 3 & 30 & 0 & 0 & 6 & 30 & 0 & 0 & 14 & 17 & 0 \\
\hline pIV & 0 & 0 & 0 & 9 & 0 & 0 & 0 & 6 & 0 & 0 & 0 & 6 \\
\hline$n$ & 10 & 18 & 37 & 9 & 5 & 26 & 35 & 6 & 17 & 26 & 23 & 6 \\
\hline
\end{tabular}

assessment again. However, we should only draw a cautious conclusion on this innovative method. Since SAA is not considered as a cancer-specific marker and an increased concentration is associated with a broad spectrum of diseases, stricter eligibility should be developed to promote the MPE system stability [33]. Moreover, other acute-phase proteins associated with metastatic lymph nodes, e.g., C-reactive protein and fibrinogen, highlight that future trials may try to compare them with SAA and determine the best one for MPE system $[12,34]$.

The MPE strategy led to a significantly increased concordance rate of prediction in surgical procedures for rectal cancer as compared with MSCT alone $(95.9 \%$ vs. $80.6 \%, P=$ 0.001). The additional analysis of this study may explain the role of preoperative staging in improving surgical decision making. Firstly, the result indicates that tumor height remains

Table 6 Expected surgical procedures preoperatively and final surgical procedures postoperatively in three arms

\begin{tabular}{lrrrr}
\hline Expected surgical procedures & $n$ & \multicolumn{3}{c}{ Final surgical procedures } \\
\cline { 3 - 5 } & & SPR & NSPR & PC \\
\hline Arm A & & & & \\
SPR & 58 & 55 & 2 & 1 \\
NSPR & 6 & 0 & 6 & 0 \\
PE & 10 & 0 & 0 & 10 \\
$n$ & 74 & 55 & 8 & 11 \\
Arm B & & & & \\
SPR & 57 & 51 & 3 & 3 \\
NSPR & 4 & 2 & 2 & 0 \\
PE & 11 & 0 & 0 & 11 \\
$n$ & 72 & 53 & 5 & 14 \\
Arm C & & & & \\
SPR & 50 & 46 & 2 & 2 \\
NSPR & 14 & 5 & 5 & 4 \\
PE & 8 & 0 & 1 & 7 \\
$n$ & 72 & 51 & 8 & 13 \\
\hline
\end{tabular}

$S P R$ sphincter-preserving radical excision, NSPR non-sphincterpreserving radical excision, and $P C$ palliative colostomy one of the primary factors that influence the choice of surgical management, provided by TRUS accurately in MPE system. With application on the current concept of concise continent resection, combined with total extirpation of the mesorectum, tumors of the upper and middle third of the rectum can be easily resected with preservation of sphincter. In tumors of the lower third, sphincter is preserved in most cases. The only exceptions are patients in whom the sphincter itself is affected or in whom a distal margin of less than $1 \mathrm{~cm}$ cannot be achieved [35]. Secondly, the local infiltration and advances, i.e., T stage, are associated with surgical procedures performed. About $15 \%$ rectal cancer involves the uterus, adnexa, posterior vaginal wall, and bladder [36, 37], which can be well-evaluated by TRUS in MPE system. En bloc resection is an aggressive surgical method to manage locally advanced, adherent colorectal tumors in order to achieve a complete resection for lesions that are staged T4 clinically and pathologically [38]. Considering the high incidence of complication, low quality of life, and improved adjuvant therapy efficacy, the palliative colostomy followed by postoperative adjuvant therapy was performed instead in the authors' institution. Other clinicopathological factors, i.e., $\mathrm{N}$ stage, TNM stage, and SAA levels, should be indirectly associated with surgical decision making. High grade of these factors always reflects the local advanced rectal cancer. Therefore, those factors mentioned above provided accurately by MPE system allow for tailoring more appropriate surgical decision making in rectal cancer. Besides, it should be noticed that the surgeon's expertise also plays a crucial role in surgical options [39].

\section{Conclusion}

In this study, MPE system is a more effective strategy than a single-imaging technique in preoperative assessment of the depth of infiltration and metastatic lymph nodes of rectal cancers. In the MPE system, TRUS is successfully used to stage local invasion, whilst MSCT combined with SAA are proven to precisely evaluate lymph node involvement. More importantly, it is a useful aid in the surgical 
Table 7 The relationship between final operative procedures and clinicopathological factors

\begin{tabular}{|c|c|c|c|c|c|}
\hline Clinicopathological factors & SPR & NSPR & $\mathrm{PC}$ & Correlation coefficient & $P$ value \\
\hline$n$ & 159 & 21 & 38 & & \\
\hline Tumor height $(\mathrm{cm})$ & $6.26 \pm 2.62$ & $4.76 \pm 2.68$ & $4.54 \pm 2.69$ & -0.147 & 0.030 \\
\hline General category & & & & -0.070 & 0.305 \\
\hline Protrude type & $51(32.1)$ & $7(33.3)$ & $19(50.0)$ & & \\
\hline Ulcer type & $95(59.7)$ & $12(57.1)$ & $13(34.2)$ & & \\
\hline Infiltrating type & $10(6.3)$ & $1(4.8)$ & $4(10.5)$ & & \\
\hline Other type & $3(1.9)$ & $1(4.8)$ & $2(5.3)$ & & \\
\hline Texture of tumor & & & & 0.066 & 0.329 \\
\hline Rigid & $108(67.9)$ & $12(57.1)$ & $31(81.6)$ & & \\
\hline Moderate & $43(27.0)$ & $6(28.6)$ & $7(18.4)$ & & \\
\hline Soft & $8(5.1)$ & $3(14.3)$ & 0 & & \\
\hline Histology & & & & 0.086 & 0.204 \\
\hline Adenocarcinoma & $134(84.3)$ & $19(90.4)$ & $33(86.8)$ & & \\
\hline Mucous adenocarcinoma & $17(10.7)$ & $1(4.8)$ & $2(5.3)$ & & \\
\hline Signet ring cell carcinoma & $2(1.2)$ & 0 & $2(5.3)$ & & \\
\hline Others & $6(3.8)$ & $1(4.8)$ & $1(2.6)$ & & \\
\hline Differentiation & & & & -0.034 & 0.621 \\
\hline Well-differentiated & $1(0.6)$ & 0 & 0 & & \\
\hline Moderately differentiated & $111(69.8)$ & $16(76.2)$ & $29(76.3)$ & & \\
\hline Poorly differentiated & $38(23.9)$ & $4(19.0)$ & $4(10.5)$ & & \\
\hline Others & $9(5.7)$ & $1(4.8)$ & $5(13.2)$ & & \\
\hline pT & & & & 0.297 & $<0.001$ \\
\hline pT1 & $11(6.9)$ & 0 & 0 & & \\
\hline pT2 & $32(20.1)$ & 0 & 0 & & \\
\hline pT3 & $20(12.6)$ & $5(23.8)$ & $2(5.3)$ & & \\
\hline pT4 & $96(60.4)$ & $16(76.2)$ & $36(94.7)$ & & \\
\hline $\mathrm{pN}$ & & & & 0.234 & $<0.001$ \\
\hline $\mathrm{pN}_{0}$ & $84(52.8)$ & $7(33.3)$ & 9 (23.7) & & \\
\hline $\mathrm{pN}_{1}$ & $75(47.2)$ & $14(66.7)$ & $29(76.3)$ & & \\
\hline $\mathrm{pM}$ & & & & 0.097 & 0.152 \\
\hline $\mathrm{pM}_{0}$ & $146(91.8)$ & $20(95.2)$ & $31(81.6)$ & & \\
\hline $\mathrm{pM}_{1}$ & $13(8.2)$ & $1(4.8)$ & $7(18.4)$ & & \\
\hline pTNM & & & & 0.290 & $<0.001$ \\
\hline I & $40(25.2)$ & 0 & $0(0)$ & & \\
\hline II & $42(26.4)$ & $7(33.3)$ & $7(18.4)$ & & \\
\hline III & $64(40.3)$ & $13(61.9)$ & $24(63.2)$ & & \\
\hline IV & $13(8.1)$ & $1(4.8)$ & 7 (18.4) & & \\
\hline Serum levels of SAA $(\mathrm{mg} / \mathrm{L})^{\mathrm{b}}$ & $8.40 \pm 13.84$ & $19.37 \pm 45.84$ & $51.46 \pm 130.34$ & 0.252 & 0.002 \\
\hline
\end{tabular}

$S P R$ sphincter-preserving radical excision, $N S P R$ non-sphincter-preserving radical excision, $P C$ palliative colostomy

${ }^{a}$ Data are numbers with percentages in parentheses

${ }^{\mathrm{b}}$ Only the data of MPE and MSCT+SAA groups were pooled into analysis

decision making of these patients mainly based on improved preoperative staging. MPE strategy could provide reliable information on pathological T, N, TNM stages, SAA levels, and tumor height which allow for appropriate stage-specific preoperative therapy and prediction of surgical procedures.
Acknowledgments We thank Mr. Shengtao Zhou for his language support to prepare this manuscript and other investigators who took part in the study: Changlong Qin, Libo Yan, and Dan Liu.

Open Access This article is distributed under the terms of the Creative Commons Attribution Noncommercial License which per- 
mits any noncommercial use, distribution, and reproduction in any medium, provided the original author(s) and source are credited.

\section{References}

1. Adam IJ, Mohamdee MO, Martin IG, Scott N, Finan PJ, Johnston D, Dixon MF, Quirke P (1994) Role of circumferential margin involvement in the local recurrence of rectal cancer. Lancet 344:707-711

2. de Haas-Kock DF, Baeten CG, Jager JJ, Langendijk JA, Schouten LJ, Volovics A, Arends JW (1996) Prognostic significance of radial margins of clearance in rectal cancer. Br J Surg 83:781-785

3. Gimbel MI, Paty PB (2004) A current perspective on local excision of rectal cancer. Clin Colorectal Cancer 4:26-35 discussion 36-27

4. Gerard JP, Chapet O, Nemoz C, Hartweig J, Romestaing P, Coquard R, Barbet N, Maingon P, Mahe M, Baulieux J, Partensky C, Papillon M, Glehen O, Crozet B, Grandjean JP, Adeleine P (2004) Improved sphincter preservation in low rectal cancer with high-dose preoperative radiotherapy: the lyon R96-02 randomized trial. J Clin Oncol 22:2404-2409

5. Gunderson LL, Haddock MG, Schild SE (2003) Rectal cancer: preoperative versus postoperative irradiation as a component of adjuvant treatment. Semin Radiat Oncol 13:419-432

6. Moran B, Brown G, Cunningham D, Daniels I, Heald R, Quirke P, Sebag-Montefiore D (2008) Clarifying the TNM staging of rectal cancer in the context of modern imaging and neo-adjuvant treatment: ' $y$ ' $u$ ' and 'p' need 'mr' and 'ct'. Colorectal Dis 10:242-243

7. Kwok H, Bissett IP, Hill GL (2000) Preoperative staging of rectal cancer. Int J Colorectal Dis 15:9-20

8. Bipat S, Glas AS, Slors FJ, Zwinderman AH, Bossuyt PM, Stoker J (2004) Rectal cancer: local staging and assessment of lymph node involvement with endoluminal US, CT, and MR imaging-a meta-analysis. Radiology 232:773-783

9. Karantanas AH, Yarmenitis S, Papanikolaou N, Gourtsoyiannis N (2007) Preoperative imaging staging of rectal cancer. Dig Dis 25:20-32

10. Malle E, De Beer FC (1996) Human serum amyloid A (SAA) protein: a prominent acute-phase reactant for clinical practice. Eur J Clin Invest 26:427-435

11. Glojnaric I, Casl MT, Simic D, Lukac J (2001) Serum amyloid A protein (SAA) in colorectal carcinoma. Clin Chem, Lab Med 39:129-133

12. Wang X, Deng L, Lv D, Li Y, Gao M, Li L (2009) Preoperative clinical diagnostic values of serum amyloid A protein in colorectal cancer patients. Sichuan Medical Journal 30

13. Wang X, Song H, Lv D, Qin C, Wu J, Li Z, Li L (2009) Randomized controlled trial of preoperatively combinative assessment of upper rectal cancer in prediction to operative strategies. Chinese Journal of Bases and Clinics in General Surgery 16

14. Thoeni RF (1991) Colorectal cancer: cross-sectional imaging for staging of primary tumor and detection of local recurrence. AJR Am J Roentgenol 156:909-915

15. Hildebrandt U, Feifel G (1985) Preoperative staging of rectal cancer by intrarectal ultrasound. Dis Colon Rectum 28:42-46

16. Greene FL, Page DL, Fleming ID, Fritz A, Balch CM, Haller DG, Morrow M (2006) AJCC cancer staging manual. Springer-Verlag Publishing, New York

17. Lahaye MJ, Beets GL, Engelen SM, Kessels AG, de Bruine AP, Kwee HW, van Engelshoven JM, van de Velde CJ, Beets-Tan RG (2009) Locally advanced rectal cancer: MR imaging for restaging after neoadjuvant radiation therapy with concomitant chemotherapy. Part II. What are the criteria to predict involved lymph nodes? Radiology 252:81-91

18. Kim SH, Lee JM, Park HS, Eun HW, Han JK, Choi BI (2009) Accuracy of MRI for predicting the circumferential resection margin, mesorectal fascia invasion, and tumor response to neoadjuvant chemoradiotherapy for locally advanced rectal cancer. J Magn Reson Imaging 29:1093-1101
19. Jhaveri KS, Sadaf A (2009) Role of MRI for staging of rectal cancer. Expert Rev Anticancer Ther 9:469-481

20. Rifkin MD, Ehrlich SM, Marks G (1989) Staging of rectal carcinoma: prospective comparison of endorectal US and CT. Radiology 170:319-322

21. Hunerbein M (2003) Endorectal ultrasound in rectal cancer. Colorectal Dis 5:402-405

22. Gollub MJ, Schwartz LH, Akhurst T (2007) Update on colorectal cancer imaging. Radiol Clin North Am 45:85-118

23. Kim JC, Kim HC, Yu CS, Han KR, Kim JR, Lee KH, Jang SJ, Lee SS, Ha HK (2006) Efficacy of 3-dimensional endorectal ultrasonography compared with conventional ultrasonography and computed tomography in preoperative rectal cancer staging. Am J Surg 192:89-97

24. Kim NK, Kim MJ, Yun SH, Sohn SK, Min JS (1998) Comparative study of transrectal ultrasonography, pelvic computerized tomography, and magnetic resonance imaging in preoperative staging of rectal cancer. In Meeting of the American-Society-of-Colon-andRectal-Surgeons, Edition San Antonio, Texas: 770-775

25. Dinter DJ, Hofheinz RD, Hartel M, Kaehler GF, Neff W, Diehl SJ (2008) Preoperative staging of rectal tumors: comparison of endorectal ultrasound, hydro-CT, and high-resolution endorectal MRI. Onkologie 31:230-235

26. Panzironi G, De Vargas Macciucca M, Manganaro L, Ballesio L, Ricci F, Casale A, Campagnano D (2004) Preoperative locoregional staging of rectal carcinoma: comparison of MR. TRUS and Multislice CT. Personal experience. Radiol Med 107:344-355

27. Goertz RS, Fein M, Sailer M (2004) Impact of biopsy on the accuracy of endorectal ultrasound staging of rectal tumors. In Digestive Disease Week/105th Annual Meeting of the American-GastroenterologicalAssociation, Edition New Orleans, LA: 1125-1129

28. Kim JH, Beets GL, Kim MJ, Kessels AG, Beets-Tan RG (2004) High-resolution MR imaging for nodal staging in rectal cancer: are there any criteria in addition to the size? Eur J Radiol 52:78-83

29. Dworak O (1989) Number and size of lymph nodes and node metastases in rectal carcinomas. Surg Endosc 3:96-99

30. Monig SP, Baldus SE, Zirbes TK, Schroder W, Lindemann DG, Dienes HP, Holscher AH (1999) Lymph node size and metastatic infiltration in colon cancer. Ann Surg Oncol 6:579-581

31. Wang X, Yin Y, Lu M, Lv D, Bai L, Shi Y, Li Z, Li L (2009) A randomized controlled trial of preoperatively combinative assessment of middle and lower rectal cancer for surgical decisionmaking Chinese Journal of Bases and Clinics in General Surgery 16

32. Wang X, Zhang Q, Lv D, Wu J, Zeng R, Li L (2009) Influence of combinative assessment of 64 multi-slice sprial computer tomography and serum amyloid A protein on surgery strategy of colon cancer. Chinese Journal of Bases and Clinics in General Surgery 16

33. Chan DC, Chen CJ, Chu HC, Chang WK, Yu JC, Chen YJ, Wen LL, Huang SC, Ku CH, Liu YC, Chen JH (2007) Evaluation of serum amyloid A as a biomarker for gastric cancer. Ann Surg Oncol 14:84-93

34. Yamashita H, Kitayama J, Nagawa H (2005) Hyperfibrinogenemia is a useful predictor for lymphatic metastasis in human gastric cancer. Jpn J Clin Oncol 35:595-600

35. Lafreniere R (2004) What's new in general surgery: surgical oncology. J Am Coll Surg 198:966-988

36. Sugarbaker PH, Corlew S (1982) Influence of surgical techniques on survival in patients with colorectal cancer. Dis Colon Rectum 25:545-557

37. Bonfanti G, Bozzetti F, Doci R, Baticci F, Marolda R, Bignami P, Gennari L (1982) Results of extended surgery for cancer of the rectum and sigmoid. Br J Surg 69:305-307

38. Nelson H, Petrelli N, Carlin A, Couture J, Fleshman J, Guillem J, Miedema B, Ota D, Sargent D, National Cancer Institute Expert Panel (2001) Guidelines 2000 for colon and rectal cancer surgery. J Natl Cancer Inst 93:583-596

39. Abbas MA (2008) Sphincter preservation for distal rectal cancer: how low is too low? Am J Clin Oncol 31:195-198 